\title{
Impacts of particulate organic carbon and dissolved organic carbon on removal of polycyclic aromatic hydrocarbons, organochlorine pesticides, and nonylphenols in a wetland
}

\author{
Jianping Luo • Mei Ma • Cao Liu • Jinmiao Zha • \\ Zijian Wang
}

Received: 27 November 2008 / Accepted: 12 March 2009/Published online: 26 March 2009

(C) Springer-Verlag 2009

\begin{abstract}
Background, aim, and scope The potential of wetlands for controlling point- and nonpoint-source pollution in surface water has attracted increasing interest. The partitioning process of organic contaminants between water, particulate organic carbon (POC) and dissolved organic carbon (DOC), impacts their behaviors in the aquatic environments. Meantime, the partitioning process of organic contaminants is closely related to their physicochemical properties, such as hydrophobicity (or $K_{\mathrm{ow}}$ ), and their fates in wetlands may vary greatly depending on physicochemical properties. The aim of this study was to examine fates and removals of polycyclic aromatic hydrocarbons (PAHs), organochlorine pesticides (OCPs) and nonylphenols (NPs) in a wetland in Beijing, China, and provide useful information for ecological remediation.

Materials and methods Water samples, collected at five sites from inlet to outlet of the wetland once a month in summer 2006, were immediately filtered within 2 days through $0.45-\mu \mathrm{m}$ glass fiber prefilters and enriched by solid-phase extraction. The filtered particulates were collected as the total suspended particulates (TSPs), freeze-dried, and Soxhletextracted. After extraction, samples were purified following a clean-up procedure and analyzed by GC-MS.
\end{abstract}

Responsible editor: Jianming $\mathrm{Xu}$

J. Luo $\cdot$ M. Ma $\cdot$ J. Zha $\cdot$ Z. Wang $(\bowtie)$

Research Center for Eco-Environmental Sciences,

Chinese Academy of Sciences,

P.O. Box 2871, Beijing 100085, China

e-mail: wangzj@rcees.ac.cn

C. Liu

Beijing Hydraulic Research Institute,

Che Gong Zhuang West Road,

Beijing 100044, China
Results TSPs could be removed efficiently with a removal rate of $97.4 \%$, and DOC could be moderately removed with a removal rate of $44.7 \%$ from inlet to outlet. The total removals of target contaminants varied widely from null to $82.0 \%$. A good correlation between $\log K_{\mathrm{ow}}$ and $\log K_{\mathrm{oc}}$ (organic-carbon-normalized suspended-particulate partition coefficient) was observed $\left(r^{2}=0.84\right.$ for PAHs and $r^{2}=0.86$ for OCPs, $p<0.01)$. Ratios of the POC-bound fraction of target contaminants (or DOC-bound fraction) to the freely dissolved fraction increased with their $K_{\mathrm{ow}}$ values. The removal of the POC fraction contributed more than $50 \%$ to the total removal for the contaminants with $\log K_{\mathrm{ow}}>5.0$. Only a small portion of the removal was attributed to the removal of the freely dissolved fraction.

Discussion Hydrophobic compounds such as PAHs and OCPs with higher $K_{\text {ow }}$ values would show stronger POC or DOC preference. Their removal depended greatly on their $K_{\text {ow }}$ values and the removal of total suspended particulates. On the other hand, concentrations of NPs decreased little in the wetland, probably due to their production through degradation of their precursors and relatively low hydrophobicity.

Conclusions POC and DOC play essential roles on the fates and removals of hydrophobic organic contaminants in the wetland. The removal of target contaminants with a high $K_{\text {ow }}$ should be mainly through association with the suspended particulates which were precipitated and retained in the wetland. The fates of the organic contaminants in the wetland greatly depended on their hydrophobicities.

Recommendations and perspectives Further work should be done to study the influence of hydraulic retention time and some other environmental factors, e.g., temperature, on removals and fates of organic contaminants. Behavior of NPs and their precursors in the wetland should also be investigated more thoroughly. 
Keywords Dissolved organic carbon · Fate ·

Organic contaminants · Particulate organic carbon · Wetland

\section{Background, aim, and scope}

The potential of wetlands for controlling point- and nonpoint-source pollution in surface water has attracted increasing interest over past decades to comply with related regulations and improve the ecological situation. Until now, available information on the performance of wetlands is mainly about general contaminant parameters, such as $\mathrm{BOD}_{5}$, nitrate nitrogen, and ortho-phosphate (U.S. EPA 1993; Belmont and Metcalfe 2003; Bezbaruah and Zhang 2003). However, some recent studies have focused on specific organic contaminants such as herbicides, pesticides, and pharmaceutical and personal care products (Matamoros et al. 2005, 2007, 2008; Matamoros and Bayona 2006; Schulz and Peall 2001; Schulz et al. 2003; Rose et al. 2006). Those studies highlighted the potential of wetlands as a risk-mitigation strategy for many water bodies polluted by organic contaminants. In China, the situation of heavy pollution and scarcity of surface water resources means that any rapid and effective treatment technologies of wastewater are highly welcome.

The mechanisms responsible for removal of organic contaminants in wetlands may include volatilization, adsorption, photolysis, hydrolysis, metabolic degradation and so on (Lewis et al. 1999). These mechanisms can be divided into two classes of processes in the aquatic environment: transport and transformation. Therefore, the removals or fates of organic contaminants in wetlands are the consequences of the two processes. Individual contaminants tend to interact with sediments, suspended particulates, water, and biota (transport processes) (Smit et al. 2008; Weber et al. 2006; Zhou and Maskaoui 2003) and be chemically and biologically transformed (Schulz et al. 2003; Gross et al. 2004) to different extents due to physicochemical properties such as vapor pressure, solubility, hydrophobicity, and biodegradability. Consequently, transport, transformation and fates of organic contaminants in wetlands greatly depend on their physicochemical properties. Organic contaminants could be classified into four groups according to their removal efficiencies: highly efficiently removed, moderately removed, poorly removed, and those recalcitrant to elimination (Matamoros et al. 2008).

Furthermore, one of the fundamental processes controlling the transport, transformation of organic contaminants, especially for hydrophobic organic compounds in aquatic environments is the partitioning and distribution between water, DOC, and POC (Qiao et al. 2008; Servos and Muir 1989; Zhou and Rowland 1997). Contaminants can exist in freely dissolved, DOC-bound, POC-bound, sediment- associated, and biota-associated forms in aquatic systems. Previous studies suggested that POC and DOC played an important role in partitioning processes (Mitra and Dickhut 1999; Chin and Gschwend 1992). Sorption to POC generally retards contaminant's transport, whereas DOC binding, such as on humic substances, may compete with POC sorption promoting the contaminant transport (Burkhard 2000). However, few studies have been conducted to investigate the effects of POC and DOC on fates and removals of organic contaminants in wetlands.

In this study, fates and removals of 16 priority PAHs, seven OCPs and NPs with different physicochemical properties such as hydrophobicity were examined in a wetland locating along one tributary before its entry into the Guanting reservoir $\left(40^{\circ} 25^{\prime} \mathrm{N}, 115^{\circ} 47^{\prime} \mathrm{E}\right)$ in Beijing, China. Agricultural, industri$\mathrm{al}$, and municipal wastewaters are discharged directly into the wetland. This catchment has been known to have relatively constant concentrations of PAHs and OCPs in surface waters and sediments (Xue et al. 2006; Huang et al. 2005). Meantime, nonylphenol ethoxylates (NPEOs) and their degradation products which can cause endocrine disrupting effects have been found widely in wastewater effluents at relatively high concentrations (Gross et al. 2004).

\section{Materials and methods}

\subsection{Chemicals and reagents}

The mixture standard solutions of OCPs $(\alpha-, \beta-, \gamma-$, and $\delta-$ hexachlorocyclohexane $[\mathrm{HCH}], p, p^{\prime}$-dichlorodiphenyldi chloroethane [DDD], $p, p^{\prime}$-dichlorodiphenyldichloroethy lene [DDE], $p, p^{\prime}$-dichlorodiphenyltrichloroethane [DDT]) and 16 priority PAHs (naphthalene [Nap], acenaphthylene [Acy], acenaphthene [Ace], fluorene [Flu], phenanthrene [Phe], anthracene [Ant], fuoranthene [Fla], pyrene [Pyr], benzo $(a)$ anthracene $[\mathrm{BaA}]$, chrysene $[\mathrm{Chr}]$, benzo $(b)$ fluoranthene $[\mathrm{BbF}]$, benzo $(k)$ fluoranthene $[\mathrm{BkF}]$, benzo $(a)$ pyrene $[\mathrm{BaP}]$, dibenz $(a, h)$ anthracene $[\mathrm{DahA}]$, indeno $(1,2,3-c d)$ pyrene $[\mathrm{IcdP}]$, benzo $(g, h, i)$ perylene $[\mathrm{BghiP}])$ and nonylphenols (a mixture of 11 isomers of 4-nonylphenols) were purchased from Supelco (Bellefonte, PA). Standards (from the same vender) of phenanthrene- $d_{10}, 2,4,5,6-$ tetrachloro- $m$-xylene, PCB209, and bisphenol A- $d_{14}$ were used as surrogates, and standards of hexamethybenzene, pentachloronitrobenzene and pyrene- $d_{16}$ as internal standards. The organic solvents of pesticide grade were obtained from Fisher Scientific (Fair Lawn, NJ).

\subsection{Constructed wetland and experiment design}

The wetland is a constructed wetland planted with phragmites australis, typha angustifulia and eichnornia crassipes (area, 
100 ha.). The hydraulic loading rate and retention time of the wetland are $0.58 \mathrm{~m} \cdot \mathrm{d}^{-1}$ and $34 \mathrm{~h}$, respectively.

Water samples were collected at five sites (site 1, 2, 3, 4, 5) from inlet (site 1) to outlet (site 5) of the wetland once a month in summer (from June to August) 2006. Water samples were immediately filtered within 2 days through $0.45 \mu \mathrm{m}$ glass fiber prefilters (Millipore, Ireland) and enriched by solidphase extraction (SPE) with HLB cartridges $(500 \mathrm{mg} / 6 \mathrm{~mL}$, Waters Co., Ireland). The filtered particulates were collected as the total suspended particulates (TSPs). At some sites, more water may be needed to filter in order to get enough particulate samples for analysis.

\subsection{Analytical methods}

Suspended particulates were freeze-dried, ground with a mortar and pestle, and kept at $-20^{\circ} \mathrm{C}$ for further analysis. POC of suspended particulates after removing the inorganic carbon with $21 \%$ phosphoric acid was analyzed by total organic carbon (TOC) analyzer (Apollo 9000, TekmarDohrmann, USA). DOC of filtered water samples were analyzed by TOC-5000 (Shimadzu, Japan).

Every HLB cartridge was eluted with $5 \mathrm{~mL}$ dichloromethane (DCM)/hexane $(1 / 2, v / v), 10 \mathrm{~mL}$ DCM/methanol $(9 / 1, v / v)$ and $5 \mathrm{~mL}$ methanol. The particulate samples extracted with $200 \mathrm{~mL}$ hexane/acetone $(1 / 1, v / v)$ in a Soxhlet apparatus for $24 \mathrm{~h}$. Activated copper was added for desulfurization. All extracts of water and particulate samples were concentrated in a rotary evaporator (Büchi R-200, Switzerland), and solvent-exchanged to hexane for clean-up under a gentle stream of nitrogen gas. The concentrated extracts for PAHs and OCPs were subjected to a glass column (10 mm i.d.) containing $15 \mathrm{~g}$ of $1 / 2$ alumina/silica gel. Firstly, the column was eluted with $15 \mathrm{~mL}$ of hexane, then was eluted with $70 \mathrm{~mL}$ of DCM / hexane $(3 / 7, v / v)$ and this fraction contained PAHs and OCPs. Eluates were then concentrated followed by adding internal standards into the final extracts prior to GC-MS analysis. Five grams alumina was used to clean up the extracts for NPs, then eluted with $20 \mathrm{~mL}$ DCM. The eluates were concentrated, derivatized with the reagent bis(trimethylsilyl)trifluoroacetamide (BSTFA), added internal standard pyrene- $d_{16}$ prior to GC-MS analysis.

The PAHs were analyzed using GC 6890N/MSD 5975 inert (Agilent Co., USA) with a HP-5 silica fused capillary column $(60 \mathrm{~m} \times 0.25 \mathrm{~mm} \times 0.25 \mu \mathrm{m})$ by $\mathrm{J} \& \mathrm{~W}$ Scientific (USA). Detection was conducted using selected-ion mode, and the details of instrument conditions were reported elsewhere (Qiao et al. 2006). Quantitation was performed using the internal calibration method based on the fivepoint calibration curve for individual components. Analysis of OCPs was carried out with an Agilent 6890 series GC equipped with a ${ }^{63} \mathrm{Ni}$ electron-capture detector (Agilent,
USA). A 30-m HP-5 column served as the primary column for pesticide identification and quantification, while a $30-\mathrm{m}$ SPB-1701column of Supelco (USA) served as the additional supportive column for pesticide confirmation. Details of the OCPs analysis have been described elsewhere (Xu et al. 2005). Another 30-m HP-5 column was used to analyze NPs using GC 6890N/MSD 5975 inert. The GC oven temperature was programmed from $50^{\circ} \mathrm{C}(2 \mathrm{~min})$ to $100^{\circ} \mathrm{C}(2 \mathrm{~min})$ at $20^{\circ} \mathrm{C} / \mathrm{min}$, then to $180^{\circ} \mathrm{C}(15 \mathrm{~min})$ at $25^{\circ} \mathrm{C} / \mathrm{min}$, and finally to $300^{\circ} \mathrm{C}$ at $20^{\circ} \mathrm{C} / \mathrm{min}(5 \mathrm{~min})$. The results were expressed as the sum of the 11 isomers and other procedures of detection and quantitation were similar to those of PAHs.

Laboratory quality-control procedures included analyses of method blanks, spiked blanks (standards spiked into solvent), matrix spikes, and sample duplicates. The average recoveries in spiked water and particulate samples fell within a fairly narrow range from $67 \pm 6 \%$ to $86 \pm 7 \%, 65 \pm$ $2 \%$ to $107 \pm 4 \%$, and $71 \pm 6 \%$ for individual PAHs, OCPs, and total NPs, respectively. Analytical results reported herein were corrected using recoveries of surrogate standards. The method detection limits (MDLs) of PAHs for water and particulate samples were 1.1 to $5.9 \mathrm{ng} / \mathrm{L}$ and 0.3 to $1.7 \mathrm{ng} / \mathrm{g}$ (dry wt), respectively. MDLs of OCPs for water and particulate samples were 0.10 to $0.16 \mathrm{ng} / \mathrm{L}$ and 0.07 to $0.12 \mathrm{ng} / \mathrm{g}$ (dry wt), respectively. MDLs of NPs for water and particulate samples were 2.8 to $6.6 \mathrm{ng} / \mathrm{L}$ and 1.7 to $5.2 \mathrm{ng} / \mathrm{g}$ (dry wt), respectively. Only very small amounts of a few low-molecular-weight PAHs with $\log K_{\text {ow }}<4.5$ were detected in method blanks, and neither detectable OCPs nor NPs were found in method blanks.

\subsection{Calculation of freely dissolved concentration}

Because the bioavailability, fates, and behaviors of organic chemicals in aquatic ecosystems are directly influenced by DOC and POC, freely dissolved concentrations can be estimated using a three-phase partitioning model (Chin and Gschwend 1992; Gschwend and Wu 1984). To examine the behaviors of different forms of contaminants in the wetland, the total concentration in water column was divided into three fractions, i.e., the freely dissolved $\left(f_{\text {free}}\right)$, the DOCbound $\left(f_{\text {DOC }}\right)$ and the POC-bound $\left(f_{\mathrm{POC}}\right)$. In this study, the concentrations of target contaminants in filtered water were analyzed which did not include the POC-bound phase, so freely dissolved concentrations could be estimated using a two-phase partitioning model:

$$
C_{\text {free }}=\frac{C_{\text {dissolved }}}{1+K_{\mathrm{DOC}} \times C_{\mathrm{DOC}}}
$$

where $C_{\text {free }}$ is the freely dissolved concentration, $C_{\text {dissolved }}$ is the concentration of the contaminant in filtered water including $f_{\text {free }}$ and $f_{\text {DOC }}, C_{\text {DOC }}$ represents concentration of 
DOC, $K_{\mathrm{DOC}}$ is partitioning coefficient of the contaminant between freely dissolved and DOC-bound phases. In present work, $K_{\mathrm{DOC}}$ was derived from $K_{\mathrm{DOC}}=0.08 K_{\mathrm{ow}}$, as proposed by Burkhard (2000). The ratios of $f_{\text {free }} / f_{\text {DOC }} / f_{\mathrm{POC}}$ were calculated based on the $f_{\text {free }}$ which is taken as the unit.

\section{Results}

3.1 Concentrations and distribution of PAHs, OCPs, and NPs in the wetland

The concentrations of TSPs and DOC, and organic carbon weight fraction $\left(f_{\text {oc }}\right)$ of the TSPs are listed in Table 1 . TSPs could be removed efficiently with a removal rate of $97.4 \%$, and DOC could be moderately removed with a removal rate of $44.7 \%$. The change of DOC along the wetland corresponded well to the change of TSPs (Table 1).

The concentrations of contaminants in filtered water $\left(C_{\text {dissolved }}\right)$ were detected by solid-phase extraction method, which included freely dissolved $\left(f_{\text {free }}\right)$ and DOC-bound $\left(f_{\text {DOC }}\right)$ fractions (Qiao and Farrell 2002; Qiao et al. 2008). Mean concentrations of PAHs, OCPs, and NPs in filtered water were summarized in Table 2. Removal rates of PAHs (excluding BghiP), OCPs, and NPs based on $C_{\text {dissolved }}$ ranged from $5.8 \%$ to $52.9 \%,-3.0 \%$ to $32.6 \%$ and $-12.4 \%$, respectively. Correlations were found between removal rates and $K_{\text {ow }}$ values of PAHs $\left(r^{2}=0.72, p<0.01\right)$ and OCPs $\left(r^{2}=0.82, p<0.01\right)$.

The ratios of $f_{\text {free }} / f_{\text {DOC }} / f_{\text {POC }}$ are listed in Table 3 for the inlet and outlet of the wetland. It was found that the ratios of $f_{\text {free }} / f_{\text {DOC }}$ for $\sum$ PAHs, $\sum$ OCPs, and NPs were $1.000 / 0.112,1.000 / 0.056$, and $1.000 / 0.016$, respectively, at the inlet (Table 3 ). The $f_{\text {DOC }}$ was larger than $f_{\text {free }}$ for contaminants with $\log K_{\mathrm{ow}} \geq 6.0$ at the inlet, where DOC and POC concentrations were the highest, and up to 8.2 times for BghiP with $\log K_{\mathrm{ow}}=6.9$. On the other hand, the ratios of $f_{\text {free }} / f_{\text {POC }}$ were $1.000 / 0.297,1.000 / 0.095$, and 1.000/0.129 for $\sum$ PAHs, $\sum$ OCPs, and NPs, respectively. The $f_{\text {POC }}$ concentrations of $\sum$ PAHs, $\sum$ OCPs, and NPs accounted for only $21.1 \%, 8.3 \%$, and $11.3 \%$ of total concentration in water column, respectively, at the inlet. However, a good correlation between $\log K_{\text {ow }}$ and $\log K_{\text {oc }}$ (dividing organic carbon-normalized concentration in sediment by $\left.C_{\text {dissolved }}\right)$ were observed $\left(r^{2}=0.84\right.$ for PAHs and $r^{2}=0.86$ for OCPs, $p<0.01$ ) (Fig. 1). In the meantime, a better correlation between $\log K_{\text {ow }}$ and $\log K_{\text {oc }}^{\prime}$ (dividing organic carbon-normalized concentration in sediment by $\left.C_{\text {free }}\right)$ was found $\left(r^{2}=0.92\right.$ for PAHs and $r^{2}=0.91$ for OCPs, $p<0.01$; Fig. 1). Thus, for contaminants with $\log K_{\mathrm{OW}}>5.5$, the ratios of $f_{\text {free }} / f_{\mathrm{POC}}$ increased from $1.000 / 0.854$ to $1.000 / 55.629$ with $K_{\text {ow }}$ values, and more than $35 \%$ of total concentration in water column occurred in $f_{\text {POC }}$, e.g., as much as $90.0 \%$ for BghiP (Table 3). Furthermore, we also found that $\log K_{\mathrm{oc}}$ values (or $\log K_{\text {oc }}^{\prime}$ values) and ratios of $f_{\mathrm{POC}}$ to $f_{\text {free }}$ for PAHs were higher than those for OCPs at the same $\log K_{\text {ow }}$ values (Fig. 1).

\subsection{Removal contributions of different fractions}

The total removal rates of PAHs, OCPs, and NPs by the wetland are shown in Table 3 , which are based on the sum of $f_{\text {free}}, f_{\text {DOC }}$, and $f_{\text {POC }}$. The removal rates ranged from null to $82.0 \%$ depending on $K_{\text {ow }}$ values. For $\sum$ PAHs, $\sum$ OCPs and NPs, the removal rates of total concentration were $34.3 \%, 12.7 \%$, and $-0.1 \%$, those of $f_{\text {free }}$ were $10.2 \%, 2.6 \%$, and $-11.6 \%$, those of $f_{\text {DOC }}$ were $4.5 \%, 2.3 \%$, and $0.5 \%$, and those of $f_{\mathrm{POC}}$ were $19.6 \%$, $7.8 \%$, and $11.1 \%$, respectively. For the contaminants with $\log K_{\text {ow }}>5.0$, total removal rates were higher than $35.7 \%$, which was considered as being moderately or efficiently removed according to Matamoros et al. (2008). For these contaminants, more than $50 \%$ of the total removal was attributed to the removal of $f_{\mathrm{POC}}$, only a small portion was attributed to the removal of $f_{\text {DOC }}$, and an even smaller portion was attributed to the removal of $f_{\text {free, }}$, whereas, for compounds with $\log K_{\text {ow }}<4.5$, the $f_{\text {POC }}$ or $f_{\text {DOC }}$ only accounted for less than $4.0 \%$ of the total, and their removals fell within the range of $15.2 \%$ to $25.1 \%$.

\section{Discussion}

Partitioning of PAHs, OCPs, and NPs between water, DOC, and POC plays a fundamental role in these contaminants' fates in the wetland, greatly depending on their $K_{\text {ow }}$ values. Many studies also showed that $K_{\text {oc }}$ values of hydrophobic contaminants in suspended particulates or sediments were closely related to their $K_{\text {ow }}$ values (Qiao et al. 2008; Karickhoff 1981; Chu and Chan 2000). It is widely acknowledged that $K_{\text {DOC }}$ is also
Table 1 Average concentrations $( \pm \mathrm{SD})$ of total suspended particulates (TSPs) and dissolved organic carbon (DOC), and organic carbon weight fraction $\left(f_{\text {oc }}\right)$ of the TSPs in the wetland $(n=3)$

\begin{tabular}{lcrrrr}
\hline & \multicolumn{1}{c}{ Site 1 } & Site 2 & Site 3 & Site 4 & Site 5 \\
\hline TSPs $(\mathrm{mg} / \mathrm{L})$ & $187.0 \pm 21.3$ & $37.9 \pm 7.9$ & $9.0 \pm 4.4$ & $3.3 \pm 2.1$ & $4.8 \pm 2.5$ \\
DOC $(\mathrm{mg} / \mathrm{L})$ & $10.3 \pm 3.2$ & $8.0 \pm 2.1$ & $6.8 \pm 1.4$ & $5.5 \pm 1.0$ & $5.7 \pm 1.2$ \\
$f_{\text {oc }}(\%)$ & $2.7 \pm 0.1$ & $2.9 \pm 0.2$ & $3.1 \pm 0.2$ & $3.0 \pm 0.1$ & $2.4 \pm 0.3$ \\
\hline
\end{tabular}


Table 2 Average concentrations of PAHs, OCPs, and NPs $(n=3, \mathrm{ng} / \mathrm{L})$ in filtered water along the wetland and their removal rates

\begin{tabular}{|c|c|c|c|c|c|c|c|}
\hline Compounds & $\log K_{\mathrm{ow}}{ }^{\mathrm{a}}$ & Site 1 & Site 2 & Site 3 & Site 4 & Site 5 & Removal rates \\
\hline Nap & 3.5 & 286.1 & 276.8 & 256.6 & 236.4 & 241.3 & $15.7 \%$ \\
\hline Acy & 4.1 & 18.8 & 19.5 & 19.6 & 18.4 & 16.4 & $12.8 \%$ \\
\hline Ace & 4.2 & 30.7 & 28.1 & 34.3 & 19.6 & 25.1 & $18.2 \%$ \\
\hline Flu & 4.4 & 53.1 & 36.7 & 29.4 & 36 & 36.7 & $14.8 \%$ \\
\hline Phe & 4.5 & 273.2 & 292.8 & 258.4 & 243.2 & 245.6 & $10.1 \%$ \\
\hline Ant & 4.5 & 60.7 & 47.6 & 61.3 & 55.1 & 57.2 & $5.8 \%$ \\
\hline Fla & 5.2 & 108.2 & 82.9 & 110.8 & 94.4 & 67.8 & $28.1 \%$ \\
\hline Pyr & 5.3 & 24.3 & 21.2 & 34.2 & 30.7 & 14.8 & $23.9 \%$ \\
\hline $\mathrm{BaA}$ & 5.9 & 35.5 & 39.6 & 42.8 & 38.7 & 21.6 & $39.2 \%$ \\
\hline Chr & 5.6 & 17.9 & 19.4 & 17.2 & 10.5 & 18.1 & $37.4 \%$ \\
\hline $\mathrm{BbF}$ & 5.8 & 34.6 & 27.3 & 36.3 & 29.8 & 21.7 & $37.3 \%$ \\
\hline $\mathrm{BkF}$ & 6.2 & 32.7 & 21.9 & 22.7 & 23.4 & 22.2 & $52.9 \%$ \\
\hline $\mathrm{BaP}$ & 6.4 & 5.9 & 4.5 & 5.1 & 4.9 & 4 & $32.2 \%$ \\
\hline IcdP & 6.5 & 2.8 & 4.4 & 4 & 3.7 & 2.5 & $40.9 \%$ \\
\hline DahA & 6.8 & 2.8 & 2.7 & 3.3 & 2.3 & 2.3 & $37.8 \%$ \\
\hline BghiP & 6.9 & $0.7^{b}$ & $0.7^{\mathrm{b}}$ & $0.7^{\mathrm{b}}$ & $0.7^{\mathrm{b}}$ & $0.7^{\mathrm{b}}$ & 0 \\
\hline$\sum \mathrm{PAHs}$ & - & 980.5 & 944.7 & 870.4 & 818.5 & 798.1 & $18.6 \%$ \\
\hline$\alpha-\mathrm{HCH}$ & 3.8 & 1.58 & 1.36 & 1.67 & 1.43 & 1.48 & $6.3 \%$ \\
\hline$\beta-\mathrm{HCH}$ & 3.8 & 4.13 & 4.53 & 3.98 & 4.05 & 4.25 & $-2.9 \%^{\mathrm{c}}$ \\
\hline$\gamma-\mathrm{HCH}$ & 3.7 & 2.16 & 1.82 & 1.91 & 1.86 & 1.94 & $10.2 \%$ \\
\hline$\delta-\mathrm{HCH}$ & 4.1 & 3.04 & 2.89 & 3.04 & 3.22 & 2.91 & $4.3 \%$ \\
\hline $\mathrm{p}, \mathrm{p}^{\prime}-\mathrm{DDE}$ & 5.7 & 0.41 & 0.37 & 0.35 & 0.27 & 0.33 & $19.5 \%$ \\
\hline p, p'-DDD & 5.5 & 0.67 & 0.55 & 0.61 & 0.58 & 0.55 & $17.9 \%$ \\
\hline p, p'-DDT & 6.2 & 0.43 & 0.37 & 0.37 & 0.24 & 0.29 & $32.6 \%$ \\
\hline$\sum \mathrm{OCPs}$ & - & 12.42 & 11.89 & 11.93 & 11.65 & 11.75 & $5.4 \%$ \\
\hline $\mathrm{NPs}^{\mathrm{b}}$ & $3.8-4.8(4.2)$ & 3367 & 3653 & 3084 & 3523 & 3415 & $-12.4 \%^{\mathrm{c}}$ \\
\hline
\end{tabular}

${ }^{\mathrm{a}} K_{\mathrm{ow}}=$ octanol/water partition coefficient. Selected values are from reference (Mackay et al. 1992) for PAHs and OCPs, and a reference (Roy and Weston 1990) for NPs

${ }^{\mathrm{b}}$ Half the method detection limit of BghiP was applied instead because it was under detection limit in filtered water but detected in suspended particulates in the wetland

${ }^{\mathrm{c}}$ Negative value indicated an increase in concentration from inlet to outlet, and considered as null removal

closely related to $K_{\text {ow }}$ (Burkhard 2000). Hence, hydrophobic compounds such as PAHs and OCPs with higher $K_{\text {ow }}$ would show stronger POC or DOC preference. Hydrophobicity-dependent partitioning of contaminants between different phases was identified as the dominant mechanism for the subsequent trapping of hydrophobic contaminants in natural waters (Mitra and Dickhut 1999; Schulz and Peall 2001). In other words, higher POC or DOC association would occur for the contaminant with higher hydrophobicity, and the ratios of $f_{\mathrm{POC}}$ (or $f_{\mathrm{DOC}}$ ) to $f_{\text {free }}$ increased with $K_{\mathrm{ow}}$. Meantime, PAHs exhibited much higher $K_{\mathrm{oc}}$ values than OCPs. This effect could result from the enhanced partition of PAHs to suspended particulates, because their planar molecular structures might enable them to gain a closer approach to aromatic components of the suspended particulates and enhance their mutual attractions (Jonker and Smedes 2000; Chiou et al. 1998).
In this study, TSPs (or POC) could be removed efficiently with a removal rate of $97.4 \%$, and DOC was reduced with a rate of $44.7 \%$. That is to say, $97.4 \%$ of the POC-bound PAHs, OCPs and NPs, and $44.7 \%$ of the DOC-bound were removed with reduction of POC and DOC. Therefore, for the contaminants with $\log K_{\mathrm{ow}}>5.0$, their removal through reducing POC and DOC contributed the overwhelming portion to the total removal in the wetland. The phenomenon that the removal of hydrophobic contaminants was affected by sorption onto the organic matter in wetlands was also observed in many other studies, such as those by Matamoros and Bayona (2006), Matamoros et al. (2008) for galaxolide and tonalide, with $\log K_{\mathrm{ow}}>5.5$, and by Rose et al. (2006) for DDE. As a result, the elimination of organic contaminants attributable to accumulation in suspended particulates which were retained in the wetland was an important 
Table 3 The ratios of $f_{\text {free }} / f_{\text {DOC }} / f_{\text {POC }}$ and different removals in the wetland

\begin{tabular}{|c|c|c|c|c|c|c|}
\hline \multirow[t]{2}{*}{ Chemicals } & \multicolumn{2}{|c|}{ Ratios of $f_{\text {free }} / f_{\mathrm{DOC}} / f_{\mathrm{POC}}$} & \multirow[t]{2}{*}{ Removal of $f_{\text {free }}$} & \multirow[t]{2}{*}{ Removal of $f_{\mathrm{DOC}}$} & \multirow[t]{2}{*}{ Removal of $f_{\mathrm{POC}}$} & \multirow[t]{2}{*}{ Total removal } \\
\hline & inlet & outlet & & & & \\
\hline Nap & $1.000 / 0.003 / 0.021$ & $1.000 / 0.002 / 0.002$ & $15.2 \%$ & $0.2 \%$ & $1.9 \%$ & $17.3 \%$ \\
\hline Acy & $1.000 / 0.013 / 0.058$ & $1.000 / 0.007 / 0.007$ & $11.4 \%$ & $0.6 \%$ & $4.9 \%$ & $16.9 \%$ \\
\hline Ace & $1.000 / 0.016 / 0.098$ & $1.000 / 0.009 / 0.004$ & $15.8 \%$ & $0.8 \%$ & $8.5 \%$ & $25.1 \%$ \\
\hline Flu & $1.000 / 0.026 / 0.053$ & $1.000 / 0.014 / 0.002$ & $12.9 \%$ & $1.3 \%$ & $4.8 \%$ & $18.9 \%$ \\
\hline Phe & $1.000 / 0.033 / 0.205$ & $1.000 / 0.018 / 0.016$ & $7.1 \%$ & $1.3 \%$ & $15.4 \%$ & $23.8 \%$ \\
\hline Ant & $1.000 / 0.033 / 0.121$ & $1.000 / 0.018 / 0.006$ & $3.8 \%$ & $1.3 \%$ & $10.0 \%$ & $15.2 \%$ \\
\hline Fla & $1.000 / 0.163 / 0.375$ & $1.000 / 0.090 / 0.037$ & $15.1 \%$ & $6.1 \%$ & $22.5 \%$ & $43.8 \%$ \\
\hline Pyr & $1.000 / 0.206 / 0.631$ & $1.000 / 0.114 / 0.045$ & $9.6 \%$ & $6.1 \%$ & $32.3 \%$ & $48.0 \%$ \\
\hline $\mathrm{BaA}$ & $1.000 / 0.818 / 1.666$ & $1.000 / 0.453 / 0.135$ & $6.8 \%$ & $13.6 \%$ & $44.9 \%$ & $65.3 \%$ \\
\hline Chr & $1.000 / 0.410 / 1.428$ & $1.000 / 0.227 / 0.116$ & $9.9 \%$ & $8.7 \%$ & $47.4 \%$ & $66.0 \%$ \\
\hline $\mathrm{BbF}$ & $1.000 / 0.650 / 1.388$ & $1.000 / 0.360 / 0.195$ & $7.9 \%$ & $12.4 \%$ & $40.8 \%$ & $61.1 \%$ \\
\hline $\mathrm{BkF}$ & $1.000 / 1.632 / 2.655$ & $1.000 / 0.903 / 0.285$ & $6.6 \%$ & $19.7 \%$ & $46.7 \%$ & $73.0 \%$ \\
\hline $\mathrm{BaP}$ & $1.000 / 2.587 / 7.046$ & $1.000 / 1.432 / 0.604$ & $0.0 \%$ & $10.9 \%$ & $60.6 \%$ & $71.4 \%$ \\
\hline IcdP & $1.000 / 3.257 / 6.472$ & $1.000 / 1.802 / 0.460$ & $1.0 \%$ & $15.3 \%$ & $56.5 \%$ & $72.7 \%$ \\
\hline DahA & $1.000 / 6.499 / 11.199$ & $1.000 / 3.596 / 0.446$ & $-0.1 \%^{\mathrm{a}}$ & $15.3 \%$ & $57.5 \%$ & $72.6 \%$ \\
\hline BghiP & $1.000 / 8.182 / 55.629$ & $1.000 / 4.528 / 1.499$ & $-1.0 \%^{\mathrm{a}}$ & $1.0 \%$ & $82.0 \%$ & $82.0 \%$ \\
\hline$\sum$ PAHs & $1.000 / 0.112 / 0.297$ & $1.000 / 0.057 / 0.025$ & $10.2 \%$ & $4.5 \%$ & $19.6 \%$ & $34.3 \%$ \\
\hline$\alpha-\mathrm{HCH}$ & $1.000 / 0.007 / 0.047$ & $1.000 / 0.004 / 0.002$ & $5.7 \%$ & $0.3 \%$ & $4.3 \%$ & $10.3 \%$ \\
\hline$\beta-\mathrm{HCH}$ & $1.000 / 0.006 / 0.030$ & $1.000 / 0.004 / 0.001$ & $-3.1 \%^{\mathrm{a}}$ & $0.3 \%$ & $2.8 \%$ & $0.0 \%$ \\
\hline$\gamma-\mathrm{HCH}$ & $1.000 / 0.005 / 0.041$ & $1.000 / 0.003 / 0.003$ & $9.5 \%$ & $0.2 \%$ & $3.7 \%$ & $13.4 \%$ \\
\hline$\delta-\mathrm{HCH}$ & $1.000 / 0.014 / 0.033$ & $1.000 / 0.008 / 0.002$ & $3.5 \%$ & $0.6 \%$ & $3.0 \%$ & $7.1 \%$ \\
\hline$p, p^{\prime}-\mathrm{DDE}$ & $1.000 / 0.516 / 0.854$ & $1.000 / 0.286 / 0.039$ & $2.1 \%$ & $10.3 \%$ & $34.5 \%$ & $46.9 \%$ \\
\hline$p, p^{\prime}-\mathrm{DDD}$ & $1.000 / 0.326 / 0.427$ & $1.000 / 0.180 / 0.042$ & $4.4 \%$ & $9.1 \%$ & $22.2 \%$ & $35.7 \%$ \\
\hline$p, p^{\prime}$-DDT & $1.000 / 1.632 / 1.785$ & $1.000 / 0.903 / 0.143$ & $1.5 \%$ & $17.9 \%$ & $37.4 \%$ & $56.8 \%$ \\
\hline$\sum \mathrm{OCPs}$ & $1.000 / 0.056 / 0.095$ & $1.000 / 0.030 / 0.006$ & $2.6 \%$ & $2.3 \%$ & $7.8 \%$ & $12.7 \%$ \\
\hline NPs & $1.000 / 0.016 / 0.129$ & $1.000 / 0.009 / 0.003$ & $-11.6 \%^{\mathrm{a}}$ & $0.5 \%$ & $11.1 \%$ & $-0.1 \%{ }^{\mathrm{a}}$ \\
\hline
\end{tabular}

${ }^{\text {a }}$ Negative values indicate an increase in concentration from inlet to outlet, and considered as null removal

removal pathway, especially for organic pollutants of high hydrophobicity in this wetland.

The wetland seemed to be unable to remove NPs. In contrast, concentration of NPs even showed some increase from the inlet to outlet. The first important reason might be that the hydrophobicity of NPs was relatively low $\left(\log K_{\mathrm{ow}}=4.2\right)$, and the ratios of $f_{\text {free }} / f_{\mathrm{POC}}$ and $f_{\text {free }} / f_{\mathrm{DOC}}$ were only $1.000 / 0.129$ and $1.000 / 0.016$, respectively, at the inlet. Thus, the proportion removed by retaining the suspended particulates was very small in the wetland. Secondly, nonylphenol ethoxylates (NPEOs) can be transformed into NPs and other intermediates in the environment (Ahel et al. 1994; Belmont and Metcalfe 2003), and the removal of NPs might be offset by their production from degradation of NPEOs. This could in part explain the increase of NPs in the wetland. Nevertheless, degradation and/or transformation of NPEOs in the wetland were not thorough because their concentrations in filtered water
Fig. 1 Relationships between $\log K_{\mathrm{ow}}, \log K_{\mathrm{oc}}$ (organic carbon-normalized partition coefficient calculated by

$C_{\text {dissolved }}$ ), and $\log K_{\text {oc }}^{\prime}$ (organic carbon-normalized partition coefficient calculated by $C_{\text {free}}$ ) of PAHs and OCPs
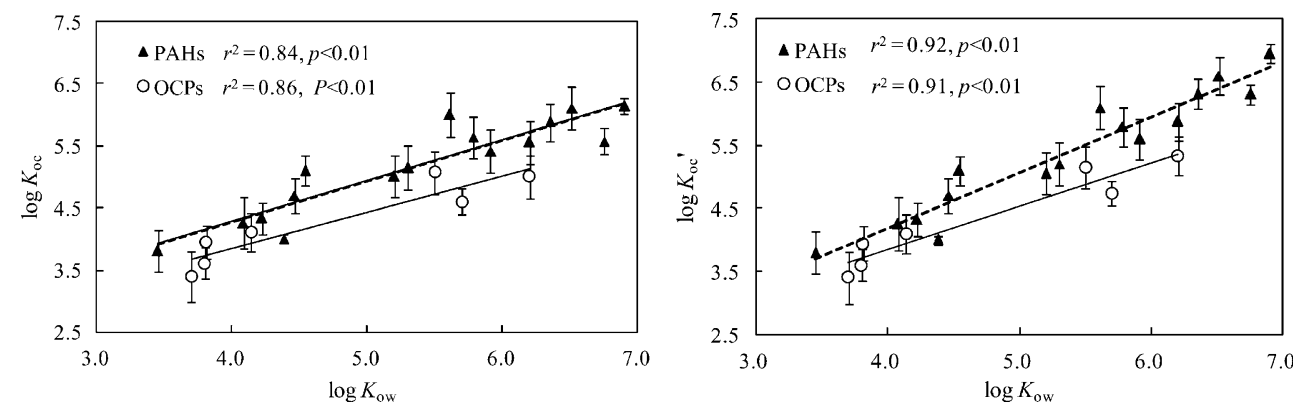
were not reduced efficiently (data not listed in this paper). This phenomenon might be due to the short hydraulic retention time (HRT) of only $34 \mathrm{~h}$ in this wetland compared with the HRT of about 1 month in Matamoros et al. (2007). Thus, there might not be enough time or capacity for removing the organic contaminants through chemical transformation and biological degradation in the wetland.

\section{Conclusions}

POC and DOC played essential roles on the fates and removals of hydrophobic organic contaminants in the wetland. The hydrophobicity of organic contaminants was the most important physicochemical property, and some other properties such as molecular structure and degradability were of secondary importance to the partitioning and distribution processes. The removals of target contaminants with high $K_{\text {ow }}$ values should mainly be through association with the suspended particulates which were precipitated and retained in the wetland.

\section{Recommendations and perspectives}

The influence of hydraulic retention time and some other environmental factors such as temperature on removal of organic contaminants was not yet fully examined in the wetland, and further work should be performed to study these factors. It is also required that behaviors of NPs and their precursors with great environmental impacts in the wetland should be investigated more thoroughly.

Acknowledgement This research has been funded by the Innovation Program of the Chinese Academy of Sciences (KZCX1-YW-06-02) and National Natural Science Foundation of China (40703025 and 20737003).

\section{References}

Ahel M, Giger W, Schaffner C (1994) Behavior of alkylphenol polyethoxylate surfactants in the aquatic environment. 2. Occurrence and transformation in rivers. Water Res 28:1143-1152

Belmont M, Metcalfe C (2003) Feasibility of using ornamental plants (Zantedeschia aethiopica) in subsurface flow treatment wetlands to remove nitrogen, chemical oxygen demand and nonylphenol ethoxylate surfactants-a laboratory-scale study. Ecol Eng 21:233-247

Bezbaruah A, Zhang T (2003) Performance of a constructed wetland with a sulfur/limestone denitrification section for wastewater nitrogen removal. Environ Sci Technol 37:1690-1697

Burkhard L (2000) Estimating dissolved organic carbon partition coefficients for nonionic organic chemicals. Environ Sci Technol 34:4663-4668
Chin Y, Gschwend P (1992) Partitioning of polycyclic aromatic hydrocarbons to marine porewater organic colloids. Environ Sci Technol 26:1621-1626

Chiou C, McGroddy S, Kile D (1998) Partition characteristics of polycyclic aromatic hydrocarbons on soils and sediments. Environ Sci Technol 32:264-269

Chu W, Chan K (2000) The prediction of partitioning coefficients for chemicals causing environmental concern. Sci Tot Environ 248:1-10

Gross B, Montgomery-Brown J, Naumann A, Reinhard M (2004) Occurrence and fate of pharmaceuticals and alkylphenol ethoxylate metabolites in an effluent-dominated river and wetland. Environ Toxicol Chem 23:2074-2083

Gschwend P, Wu S (1984) On the constancy of sediment-water partition coefficients of hydrophobic organic pollutants. Environ Sci Technol 19:90-96

Huang S, Wang Z, Xu Y, Ma M (2005) Distribution, sources and potential toxicological significance of polycyclic aromatic hydrocarbons (PAHs) in Guanting Reservoir sediments, China. J Environ Sci 17:48-53

Jonker M, Smedes F (2000) Preferential sorption of planar contaminants in sediments from Lake Ketelmeer, the Netherlands. Environ Sci Technol 34:1620-1626

Karickhoff S (1981) Semi-empirical estimation of sorption of hydrophobic pollutants on natural sediments and soils. Chemosphere 10:833-846

Lewis M, Mayer F, Powell R, Nelson M, Klaine S, Henry M, Dickson G (1999) Ecotoxicology and risk assessment for wetlands. Society of Environmental Toxicology and Chemistry (SETAC), Pensacola, FL, pp 315-342

Mackay D, Shiu W, Ma K (1992) Illustrated handbook of physicalchemical properties and environmental fate for organic compounds. Lewis, Boca Raton, FL, USA

Matamoros V, Bayona J (2006) Elimination of pharmaceuticals and personal care products in subsurface flow constructed wetlands. Environ Sci Technol 40:5811-5816

Matamoros V, García J, Bayona J (2005) Behavior of selected pharmaceuticals in subsurface flow constructed wetlands: a pilot-scale study. Environ Sci Technol 39:5449-5454

Matamoros V, Arias C, Brix H, Bayona J (2007) Removal of pharmaceuticals and personal care products (PPCPs) from urban wastewater in a pilot vertical flow constructed wetland and a sand filter. Environ Sci Technol 41:8171-8177

Matamoros V, García J, Bayona J (2008) Organic micropollutant removal in a full-scale surface flow constructed wetland fed with secondary effluent. Water Res 42:653-660

Mitra S, Dickhut R (1999) Three-phase modeling of polycyclic aromatic hydrocarbon association with pore-water-dissolved organic carbon. Environ Toxicol Chem 18:1144-1148

Qiao P, Farrell A (2002) Influence of dissolved humic acid on hydrophobic chemical uptake in juvenile rainbow trout. Comp Biochem Physiol C 133:575-585

Qiao M, Wang C, Huang S, Wang D, Wang Z (2006) Composition, sources, and potential toxicological significance of PAHs in the surface sediments of the Meiliang Bay, Taihu Lake, China. Environ Int 32:28-33

Qiao M, Huang S, Wang Z (2008) Partitioning characteristics of PAHs between sediment and water in a shallow lake. J Soils Sediments $8(2): 69-73$

Rose M, Sanchez-Bayo F, Crossan A, Kennedy I (2006) Pesticide removal from cotton farm tailwater by a pilot-scale ponded wetland. Chemosphere 63:1849-1858

Roy F, Weston Inc (1990) Determination of the vapor pressure of 4nonylphenol. Final Report Study No. 90-047. Roy, F., Weston Inc., Environmental Fate and Effects Laboratory, 254 Welsh Pool Road, Lionville, PA. 15 August 1990 
Schulz R, Peall S (2001) Effectiveness of a constructed wetland for retention of nonpoint-source pesticide pollution in the Lourens River Catchment, South Africa. Environ Sci Technol 35:422426

Schulz R, Hahn C, Bennett E, Dabrowski J, Peall S (2003) Fate and Effects of azinphos-methyl in a flow-through wetland in South Africa. Environ Sci Technol 37:2139-2144

Servos M, Muir D (1989) Effect of suspended sediment concentration on the sediment to water partition coefficient for 1, 3, 6, 8tetrachtorodibenzo-p-dioxin. Environ Sci Technol 23:1302-1306

Smit M, Grotenhuis T, Bruning H, Rulkens W (2008) Desorption of dieldrin from field aged sediments: simulating flood events. J Soils Sediments 8:80-85

U.S. Environmental Protection Agency (1993) Constructed wetlands for wastewater treatment and wildlife habitat, 17 case studies (EPA832-R-93-005)
Weber J, Kreutzmann J, Plantikow A, Pfitzner A, Claus E, Manz W, Heininger P (2006) A novel particle contact assay with the yeast Saccharomyces cerevisiae for ecotoxicological assessment of freshwater sediments. J Soils Sediments 6:84-91

Xu Y, Wang Z, Ke R, Khan SU (2005) Accumulation of organochlorine pesticides from water using triolein embedded cellulose acetate membranes. Environ Sci Technol 39:1152-1157

Xue N, Zhang D, Xu X (2006) Organochlorinated pesticide multiresidues in surface sediments from Beijing Guanting reservoir Water Res 40:183-194

Zhou J, Maskaoui K (2003) Distribution of polycyclic aromatic hydrocarbons in water and surface sediments from Daya Bay, China. Environl Pollut 121:269-281

Zhou J, Rowland S (1997) Evaluation of the interactions between hydrophobic organic pollutants and suspended particles in estuarine waters. Water Res 31:1708-1718 